\title{
Percepción de la formación y exigencia académica de los docentes universitarios enfocada al impulso de la investigación cientifica
}

\author{
Perception of the academic training and exigency of university \\ professors focused on the promotion of scientific research
}

\author{
Neisser Pino Romero ${ }^{1}$ \\ Frank Henry Acasiete Quispe ${ }^{2}$
}

\begin{abstract}
RESUMEN
La formación académica de los docentes universitarios ha sido la base de la generación de conocimientos en búsqueda del desarrollo científico mediante el desarrollo de investigaciones entre los profesores y los estudiantes en conjunto. Con lo cual, la formación universitaria debe enfocar y dedicar la interacción entre la visión científica, humanística y social de los estudios universitarios. En los últimos años se ha centrado la perspectiva de realizar una formación universitaria focalizada en la investigación constante que se relacione los estudiantes universitarios para la generación de conocimientos a un nivel científico y académico. Por lo cual, el crecimiento
\end{abstract}

1 Docente de la Facultad de Ciencias Matemáticas de la Universidad Nacional Mayor de San Marcos. Docente de la Facultad de Ciencias y Filosofía de la Universidad Peruana Cayetano Heredia. Investigador Visitante en Carleton University (Canadá). Magíster en Matemática Aplicada con mención en Matemática Computacional (UNMSM). Licenciado en Computación Científica (UNMSM).

E-mail: neisser.pino@unmsm.edu.pe,neisser.pino@upch.pe

2 Investigador en el Laboratorio Nacional de Computación Científica (LNCC). Maestro en Modelage Computacional (LNCC). Bachiller en Computación Científica (UNMSM).

E-mail: frankhaq@lncc.br

(C) Los autores. Este artículo es publicado por Pensamiento Crítico de la Facultad de Ciencias Económicas, Universidad Nacional Mayor de San Marcos. Este es un artículo de acceso abierto, distribuido bajo los términos de la licencia Creative Commons Atribucion - No Comercia_Compartir Igual 4.0 Internacional. (http://creativecommons.org/licenses/by-nc-sa/4.0/) que permite el uso no comercial, distribución y reproducción en cualquier medio, siempre que la obra original sea debidamente citada. 
de la calidad educativa se ve vinculada con la generación de conocimientos y proyectos de investigación para incrementar el nivel de la educación superior del país. Palabras clave: Formación académica; Investigación científica; Calidad educativa; docencia universitaria; ley universitaria.

JEL: I21

\section{ABSTRACT}

The academic selection of university teachers has been the basis of the generation of knowledge in the development of scientific development by the development of research among professors and students as a whole. With this, the university education should focus and dedicate the interaction between the scientific, humanistic and social vision of university studies. In recent years he has focused on the prospect of a university education focused on constant research that is related to university students for the generation of knowledge at a scientific and academic level. Therefore, the growth of educational quality is linked to the generation of knowledge and research projects to increase the level of higher education in the country.

Keywords: Academic background; Scientific research; Educational quality; University teaching; university law.

JEL: I21

\section{Introducción}

La formación académica que se puede recibir en la universidad viene a ser algo distinto pero similar a la recibida en la formación básica regular (colegio) donde los profesores enseñan mediante diferentes técnicas pedagógicas para que los niños, adolescentes y jóvenes puedan aprender y comprender las diferentes ciencias que se deben conocer de acuerdo al plan curricular vigente en Perú, que incluyen los de educación inicial (2 años), educación primaria (6 años) y educación secundaria (5 años) respectivamente en ese orden para que se impartan en los centros educativos como lo dispone el Ministerio de Educación (MINEDU). Esta perspectiva se va generando los conocimientos básicos y elementales para poder afrontar los temas que se estudiaran en la universidad de acuerdo al área de la ciencia escogida. No hay duda que la concepción que se tiene de la formación universitaria es la puerta al acceso de una formación académica superior como corresponde la secuencia académica prevista por el estado para la educación de los ciudadanos. 
En la universidad sea pública o privada tiene quizás un diferente enfoque de la formación académica como base fundamental en la preparación de los estudiantes en las áreas de la ciencia que han escogido, en este sentido se puede considerar cinco áreas de las carreras profesionales según la distribución que realiza la Universidad Nacional Mayor de San Marcos cuales son las siguientes: ciencias de la salud, ciencias básicas, ingenierías, ciencias económicas y de gestióny humanidades, ciencias jurídicas y sociales. Con estas áreas se enfocaría una adecuada formación académica para afrontar los problemas de la sociedad, y sin lugar a duda, los docentes universitarios son la base y el eje fundamental de esta preparación en complemento de la universidad, las empresas e instituciones que busquen el bien común de las personas.

Según Guerra (1979), los diferentes países generan conocimientos y tecnologías para su desarrollo como país, y de manera esencial para la sociedad, mejorando la calidad de vida de los sus habitantes. Pero este desarrollo va de la mano con la educación y la investigación científica de una manera constante y continua. Los países que invierten una gran cantidad de dinero en la educación y de manera particular en la investigación tienden a generar conocimientos propios que pueden ser utilizados para el mejoramiento y perfeccionamiento de diversos métodos que son utilizados en el día a día. Por lo cual, la formación académica debe ser exigente y de una calidad formativa enfocada en generar conocimiento mediante la investigación científica pero también en estos mismos últimos años se ha generado la percepción estudiantil de los docentes universitarios para ayudarlos a recibir una formación que les permite generar una mejor posición académica y laboral donde esta perspectiva es complemento para el fin que se busca al estudiar una carrera universitaria.

Desde luego, el poder describir la problemática de una adecuada formación académica es bastante complejo por lo cual nos centraremos en la formación académica del docente y como los estudiantes generan un idea de la posible formación que podrían recibir del docente y del mismo las exigencias que el docente realizara en el desarrollo del curso universitario.

Una de las interrogantes sobre la formación académica profesional es seguir el camino de la investigación para poner al servicio de la sociedad, por lo cual de acuerdo a nuestro secuencia de la formación superior 
se puede explicar la secuencia que se muestra en la referencia que realiza la ley universitaria. Por lo que hay que tener en cuenta que para acceder a la maestría no es necesario el título profesional, debido que no es un grado académico, solo basta con poseer el grado académico de Bachiller, según las normas de acceso a la maestría según la Universidad Nacional Mayor de San Marcos y como todas las universidades peruanas, donde los requisitos para acceder a la maestría se puede encontrar en la página web de la universidad, de manera particular de la Universidad Nacional Mayor San Marcos.

De manera específica, los requisitos académicos exigen lo siguiente: una copia del diploma de bachiller legalizado o fedateado por la universidad de procedencia, una copia del certificado de estudios universitarios de pregrado legalizado o fedateado por la universidad de procedencia y una copia del documento de identidad (DNI, carné de extranjería o pasaporte), teniendo en cuenta que los graduados en el extranjero, los grados y títulos deberán estar revalidados o reconocidos según las normas vigentes en el país.

La perspectiva de la formación académica en general tanto de la educación básica (centro educativo inicial y colegio) y la educación superior (universidad) se puede expresar mediante la siguiente grafica donde se representa toda la formación académica, el cual ayudará bastante a la perspectiva de una adecuada formación académica que actualmente se busca según ley universitaria $\mathrm{N}^{\circ} 30220$, en cuanto a una formación académica orientada a la investigación científica y así a la generación de conocimiento para seguir buscando una mejor calidad de vida y progreso para cada comunidad, sociedad, región, y país. Más aún ahora, con la globalización y el trabajo interdisciplinario que se genera a nivel mundial donde la barrera geográfica ya no es un problema. Como lo expresa de manera similar Vargas, Chiroque y Vega (2016) sobre la docencia universitaria que debe enfocarse en lineamientos de investigación colaborativo.

De esta manera, en Perú, la institución encargada de velar por el adecuado proceso de formación educativa es el ministerio de Educación (MINEDU). Quien es el encargado de gestionar la educación y garantizar el acceso de todos los peruanos, ha dividido en cuatro etapas la educación, siendo las tres primeras de carácter obligatorio, todo estos detalles es expresado en la Ley General de Educación, ley Nº 28044 (2003) y su regla- 
mento aprobado de acuerdo a ley (2012). Y con respecto a la ley sobre la educación superior tiene su ley propia que es la ley $\mathrm{N}^{\circ} 30220$.

El gráfico 1 presenta las etapas que una persona pasa para ir creciendo en el área académica y cuál es implicancia de cada etapa de una manera sencilla y comprensiva.
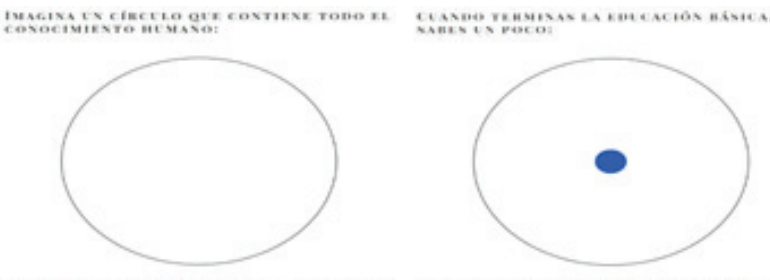

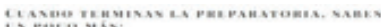
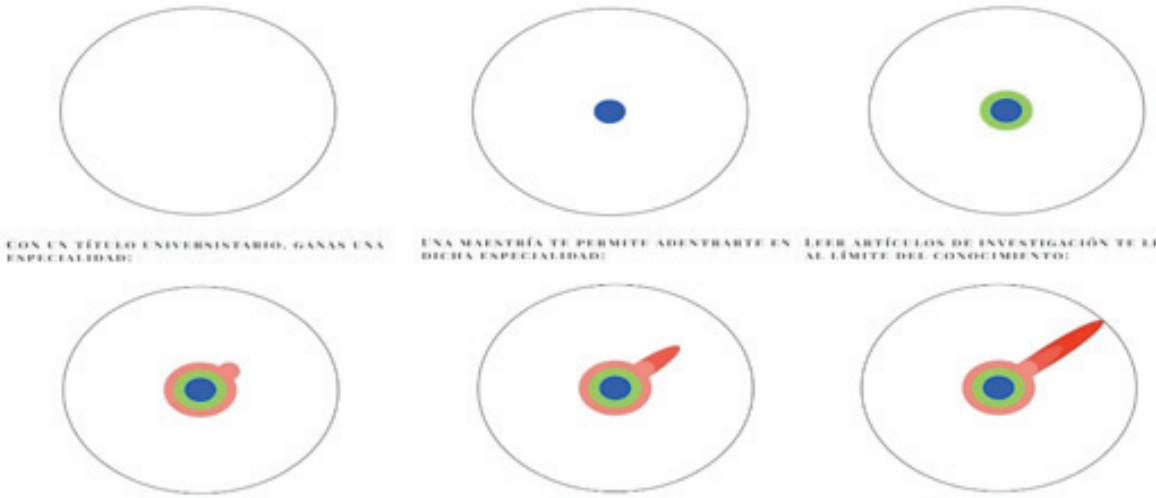

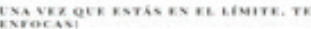

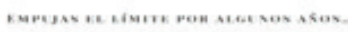

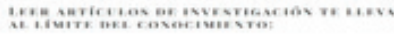
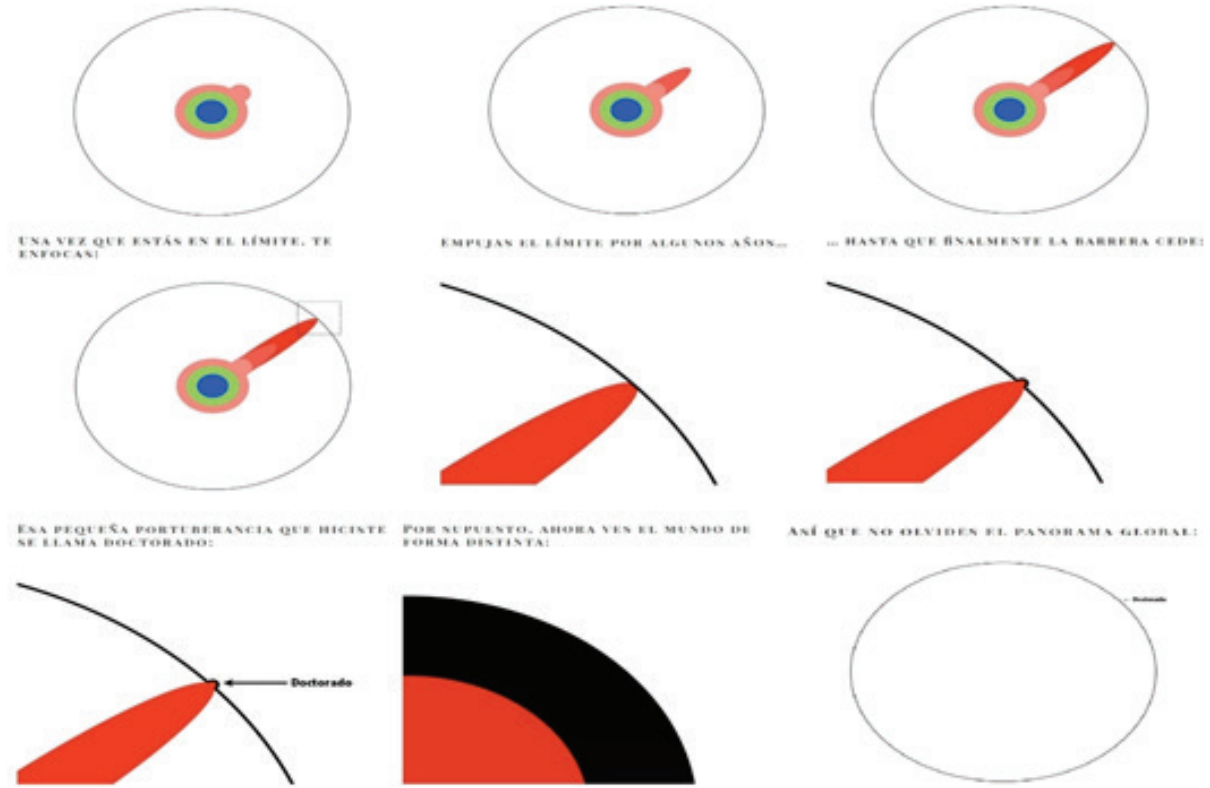

Gráfico 1. Secuencia de las etapas de la formación académica desde la educación básica hasta la educación superior

Fuente: Doctorado: una guía ilustrada. Blog: Desde mi Asteroide. David Valle 
En el presente trabajo de investigación nos centraremos en la educación superior de manera específica en la formación de pregrado de acuerdo a las nuevas directrices de la ley universitaria $\mathrm{N}^{\circ} 30220$ del capítulo de los docentes sobre los requisitos para ejercer la docencia universitaria mediante un trabajo de análisis descriptivo donde se desarrollara los datos obtenidos para inferir la situación actual ante esta problemática.

\section{Perspectiva de la ley universitaria en relación al requisito para ejercer la docencia universitaria}

La formación académica de los docentes universitarios debe alinearse con los principios y funciones de la universidad. Estos principios y funciones son enunciados en la ley universitaria vigente en el país, la ley $\mathrm{N}^{\circ} 30220$, en sus primeros artículos.

El artículo 5 de la ley universitaria describe sobre los principios de la universidad que se basan en la búsqueda y difusión de la verdad, el espíritu crítico y de investigación, el mejoramiento continuo de la calidad académica generando creatividad e innovación. Estos principios ayudan y dirigen que la universidad (pública y privada) pueda generar una adecuada pertinencia de la enseñanza e investigación con la realidad social. Y de manera similar se enfoque el artículo 6 de la ley universitaria sobre la descripción de los fines de la universidad como son: preservar, acrecentar y transmitir de modo permanente la herencia científica, tecnológica, cultural y artística de la humanidad. Todo esto enfocado a formar profesionales de alta calidad de manera integral y con pleno sentido de responsabilidad social de acuerdo a las necesidades del país y difundir el desarrollo universal en beneficio de la humanidad. De esta forma se va delineando la finalidad y las funciones de la universidad peruana como fuente de conocimiento e investigación. Y la transición de la actúa ley con la actual ley universitaria tiene que ver mucho con las perspectivas de la calidad educativa y académica que el país necesita para mantenerse al nivel de los otros países.

Con respecto a la ley $\mathrm{N}^{\circ} 23733$ (antigua ley universitaria)en el capítulo $\mathrm{V}$ (de los profesores) mediante su artículo 45, se exigía para el ejercicio de la docencia universitaria a nivel de pregrado lo siguiente: 
Para el ejercicio de la docencia ordinaria en la Universidad es obligatorio poseer grado académico de Maestro o Doctor o título profesional, uno y otro, conferidos por las Universidades del país o revalidados según ley.

Y este mismo requisito se ha modificado con la ley $\mathrm{N}^{\circ} 30220$ (actual ley universitaria) en su capítulo IV (docentes) específicamente en su artículo 82 expresa las consideraciones para ejercer la docencia a nivel pregrado. De manera exacta en su artículo 82.1 indica lo siguiente:

El grado de Maestro (Magister) para la formación en el nivel de pregrado.

Como se puede observar, el cambio del requisito sobre la formación académica exigida para poder ejercer la docencia universitaria a nivel de pregrado es la obtención del grado académico de Maestro (magister), lo cual es un tiempo adicional de formación académica que el título profesional.

En esta situación, muchos de los profesores se han dedicado a ingresar al programa de maestría de alguna universidad para obtener el grado de maestro y así cumplir con el requisito de la ley universitaria. El proceso de obtener el grado de maestro es mucho más detallada y secuencial como se dice entre los estudiantes. Debido que uno puede ser reconocido como maestro (magister) cuando ya está emitido su diploma que lo reconozca como tal, todo lo anterior no se le puede considerar como magister.

En la Universidad Nacional Mayor de San Marcos, como en muchas universidades se exige como requisitos académicos el poseer el diploma de bachiller y el certificado de estudios de pregrado para poder acceder a la maestría como lo expresa en su página web en la sección de posgrado (maestría y doctorado).

El motivo principal de este artículo de investigación se centra en la percepción de los estudiantes hacia sus docentes en cuanto a su formación académica y experiencia profesional. Como se mencionó con respecto a la ley universitaria, el grado de maestro para poder ser docente universitario es el requisito fundamental para ser docente, no se está distinguiendo las dos tipos de docentes nombrado o contratado, el cual como indica la ley se exige el grado de maestro o magister pero no se hace referencia a que orientación debe ser la maestría. 
Esta circunstancia permite la realización de estudios de posgrado en el área que más interese al docente para poder obtener el grado académico de tal manera que se satisfaga el requisito para mantenerse o acceder a la docencia universitaria de acuerdo a las exigencias actuales de la ley universitaria que rige la formación universitaria del país.

\section{Realidad de la formación académica de la universidad orien- tado a las áreas profesionales de los docentes universitarios}

La Universidad Nacional Mayor de San Marcos (UNMSM) distribuye todas sus escuelas académicos profesionales (carreras profesionales) en áreas respectivas a su enfoque formativo y científico. Según el catálogo de carreras profesionales de la Oficina Central de Admisión (OCA) de la universidad se distribuye de la siguiente manera:
A. Ciencias de la Salud
B. Ciencias Básicas
C. Ingenierías
D. Ciencias Económicas y de la Gestión
E. Humanidades, y Ciencias Jurídicas y Sociales

Desde esta perspectiva se puede considerar que todas las carreras profesionales están consideradas en estas cinco áreas. Como mencionó Pino (2017) se puede clasificar las carreras adecuadamente a su enfoque de investigación de acuerdo a su lineamiento de formación académica y científica siendo los pilares de la universidad de acuerdo a los artículos de los principios y fines de la ley universitaria. Las diferentes áreas de las carreras profesionales expresan las necesidades de la sociedad para la búsqueda de una mejor calidad de vida.

Se realizó dos encuestas de manera objetiva a dos poblaciones importantes para esta investigación, una a docentes universitarios que tienen solamente el título profesional y otra a estudiantes de pregrado. Para la realización de las encuestas se ha recurrido a un formato de preguntas de alternativa múltiple y mediante vía virtual mediante la aplicación de los Formularios de Google para facilitarnos la recopilación de datos y el análisis descriptivo de los resultados. 
Como se ha mencionado, los docentes universitarios forman de acuerdo a sus especialidades requeridas para cada carrera profesional de acuerdo a su plan de estudios. De acuerdo a esta perspectiva se genera que la formación académica del docente universitario sea más actualizada y preparada que sea posible. En este sentido se ha orientado la ley universitaria que intenta mejorar la preparación, formación y exigencia a un nivel más alto que se adecue a los estándares de calidad de la educación superior como lo expresan algunas acreditadoras que realizan esta labor. Entre las cuales se puede resaltar Sistema Nacional de Evaluación, Acreditación y Certificación de la Calidad Educativa(SINEACE) donde expresa su labor para el mejoramiento de la calidad educativa a nivel superior, esta información puede ser consultada y revisada en su respectiva página web.

Se realizó una pequeña a los docentes universitarios de diversas universidades tanto públicas como privadas, se ha tenido una base de datos de 400 profesores donde se ha realizado únicamente tres preguntas objetivo como una referencia para otra encuesta realizada a los estudiantes. En primer lugar, se obtuvo los datos referentes a los docentes y a la institución que laboran como prioridad académica donde se obtuvo los siguientes resultados.

Donde se obtuvo un 69.2\% (277 docentes) que realizan la docencia en la universidad pública de manera prioritaria del total de docentes encuestados. Por mientras que se obtuvo un 30.8\% (123 docentes) que realizan la docencia en la universidad privada.

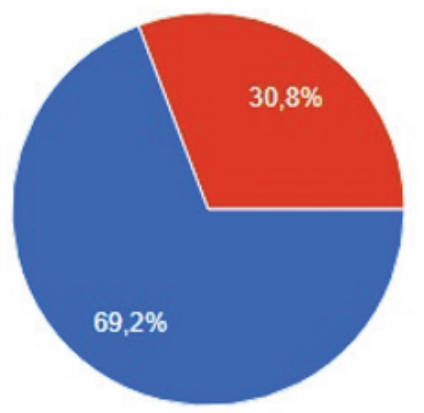

Publica

Privada

Gráfico 2. Distribución del tipo de universidades donde los profesores universitarios ejercen la docencia superior

Fuente: Elaboración propia 
Teniendo en cuenta la distribución donde se realizan la docencia universitaria los profesores, se realizó la pregunta que tiene relación con respecto al artículo 84 de la ley universitaria que indica que el docente debe poseer el grado académico de magister (maestro) como mínimo para realizar la docencia a nivel de pregrado. De los profesores encuestados se obtuvo un distribución casi distintiva que los docentes no cuentan con el grado de magister, el porcentaje indicado es $61.5 \%$ (246 docentes), lo cual se realizó una consulta a algunos docentes el motivo lo que indicaron que habían realizado los estudios de maestría o están cursando en la actualidad. Algunos ya realizaron la sustentación de la tesis pero aún les falta reunir de los requisitos exigidos por la universidad para el inicio de los trámites documentarios.

Por otro lado, se ha obtenido un 23.5\% (94 docentes) que cuentan con el grado de magister con lo cual reúnen el requisito para seguir ejerciendo la docencia universitaria a nivel de pregrado como a nivel de posgrado (programa de maestría). Se tiene la consideración que dentro de los 154 docentes que poseen el grado de maestría, se tiene a 45 docentes con el grado académico de doctor con lo cual pueden seguir ejerciendo la docencia universitaria en todos los niveles de formación tanto en pregrado como en posgrado.

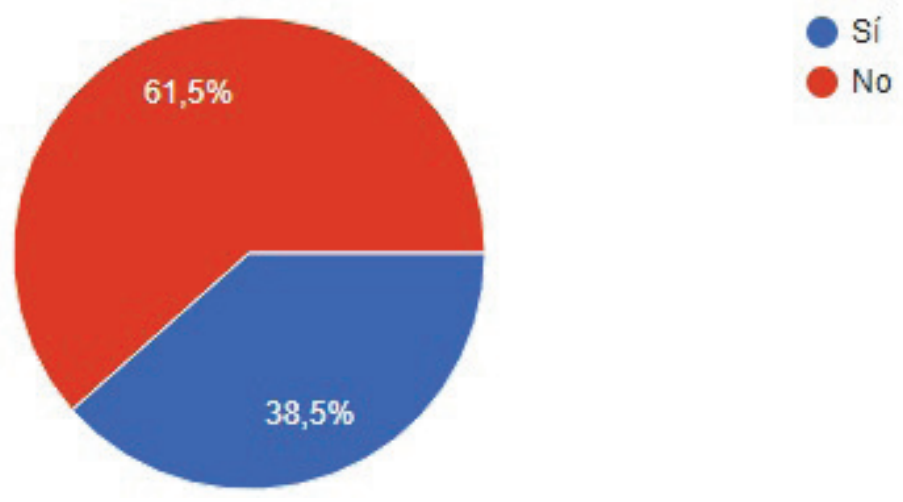

Gráfico 3. Distribución de los docentes universitarios que poseen el grado académico de magister (maestro)

Fuente: Elaboración propia 
De esta manera se obtuvo los datos estadísticos en relación a la situación actual de su formación académica, de manera específica sobre la maestría que ha realizado, o está realizando, o piensa realizar. Esto conlleva su enfoque de cumplir el requisito exigido por la ley universitaria.

Una parte de los docentes (60 profesores) expresó que está realizando sus estudios de maestría de los cuales la gran mayoría lo está realizando en otra especialidad distinta a la obtenida en su formación de pregrado. Y de los docentes que poseen su grado académico de magister también representa un porcentaje significativo que su programa de maestría es distinta a la de formación de pregrado. En esta cuestión, se podría analizar el motivo del porque se realizó un programa distinto a la formación de pregrado, pero este enfoque no es parte principal de la presente investigación desde la perspectiva de los docentes. Pero si lo enfocaremos desde la perspectiva de los estudiantes en la siguiente sección del artículo.

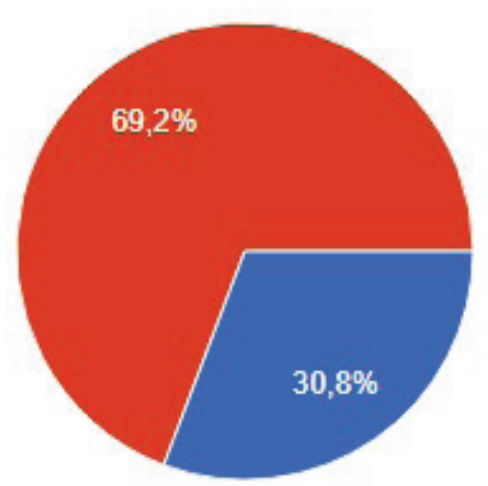

Gráfico 4. Distribución de los docentes que poseen el grado de magister o están realizado sus estudios de maestría

Fuente: Elaboración propia

Ha surgido una gran disyuntiva de una adecuada formación académica que los docentes deberían realizar para lograr una mejor transmisión del conocimiento que pueda generar ciencia y cultura en el mundo actual. Debido que la exigencia del grado de magister es en el sentido obligatorio para seguir ejerciendo la docencia universitaria. 


\section{Percepción de los estudiantes ante la formación académica de los docentes universitarios}

En esta sección se presentara dos visiones de la nueva ley universitaria, la cual está vigente hasta el día de hoy en el país peruano, la visión sobre el requisito mínimo para poder realizar la docencia universitaria a nivel de pregrado en el artículo 84 del capítulo 4 de la ley y la percepción que tiene los estudiantes sobre este requerimiento. Esta perspectiva se complementa la visión de los docentes y de los estudiantes que son las bases del crecimiento de la universidad. Para ejercer la docencia universitaria del nivel de pregrado y qué impacto realiza en la formación académica en los estudiantes universitarios. Estas perspectivas se centran en generar una mejor calidad y exigencia de la formación académica de acuerdo a los fines de la actual ley universitaria.

Como mencionanGuerra (1979) y Barahona (2015), mucho de la generación de conocimientos se debe a una adecuada formación académica que impulse la investigación en todo momento, de tal manera que las nuevas generaciones continúen con una tradición de investigación constante. En esta misma perspectiva lo manifestó Pino (2017), con respecto a una formación académica de investigación constante en el área profesional de todas las Escuelas Académicas Profesionales que se imparten en el país; también Coraggio (1996) expresa una renovación universitaria y pedagógica en la enseñanza superior para complementar la exigencia de la investigación científica y didáctica de enseñar la rigurosidad de investigación.

De esta forma lo manifiestan Pino y Flores (2017), que las decisiones que buscan nuevos horizontes pueden ser no aceptados en un inicio por el mido quizás a un sendero desconocido, difícil, innecesario, complicado; quizás sean las palabras de muchas personas han pensado sobre el requisito para ejercer la docencia universitaria a nivel de pregrado.

Para este hecho, se ha realiza una encuesta virtual mediante el Formulario Google donde se ha considerado 35 preguntas de elección múltiple y 5 preguntas de respuesta libre. La encuesta se realizó del mismo modo que el realizado a los docentes para el presente trabajo de investigación. Con respecto a la población de estudiantes que se ha considerado para la encuesta ha sido 1000 estudiantes de diversas universidades y de 
ambos tipos (pública y privada) que están cursando durante el tiempo de investigación, la cual se ha realizado en dos partes, la primera desde noviembre 2017 hasta enero 2018 para la formalización de la directriz de la investigación, por mientras que desde enero 2017 hasta julio del 2018 se realizó la recopilación de los datos mediante las encuestas de donde se realizara el análisis e interpretación de los datos.

Las preguntas de la encuesta se enfocan en el acuerdo o desacuerdo de ciertos criterios ya establecidos actualmente por la ley universitaria, como también por posibles consideraciones ante la perspectiva propuesta en el presente artículo. Una de las directrices que se ha tenido en la presente encuesta las consideraciones básicas de la situación actual de los encuestados: edad, sexo, tipo de universidad, área de estudio, año actual de estudio. Estos datos nos permitirán conocer sobre el conocimiento sobre los lineamientos que exige la ley universitaria.

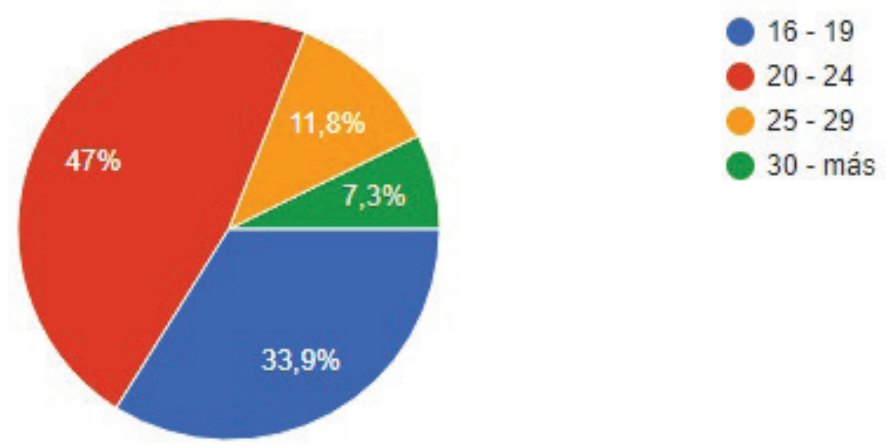

Gráfico 5. Distribución de la edad de los estudiantes universitarios Fuente: Elaboración propia

La edad de los estudiantes es de manera fundamental una referencia sobre la perspectiva que tiene en un sentido general sobre lo que busca en su formación académica y la visión de profesional que necesita ser para lograr sus objetivos. De la población de los estudiantes considerados para el presente trabajo de investigación se ha tenido un $47 \%$ que su edad se encuentra entre 20 y 24 años, siendo un intervalo de edad donde la mayoría ya tiene una visión de lo que quiere lograr con la formación académica. Por mientras que el segundo intervalo predominante tiene un $33.9 \%$ el cual se encuentran entre 16 y 19 años, donde la perspectiva de formación 
académica considerada por los estudiantes es de enfocarse más a su formación académica y no tan laboral. Se ha tenido una población de 11.8\% que se encuentran entre 25 y 29 años de edad. Finalmente se ha tenido un $7.3 \%$ que se encuentran en el cuarto sector de los estudiantes mayores de 30 años.

Una consideración importante que se ha tenido con respecto a los estudiantes ha sido su sexo, donde se ha obtenido un total de 459 estudiantes hombres (45.9\%) y un total de 541 estudiantes mujeres (54.1\%). Como se puede observar la población mayoritaria ha sido femenina para la presente investigación. Se obtuvo los datos referenciales a los estudiantes ha sido con respecto a la universidad donde se están formando académicamente, lo cual ayudará a visualizar la distribución de los estudiantes de pregrado en cuanto al tipo de la universidad donde están estudiando.
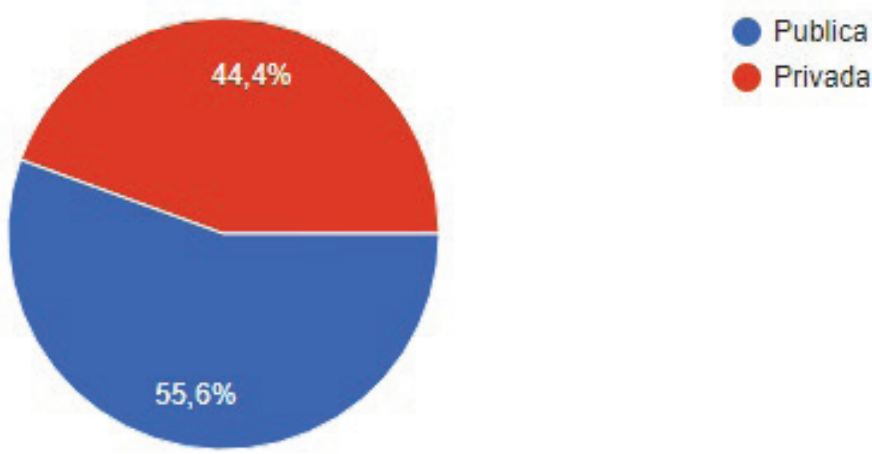

Gráfico 6. Distribución del tipo de universidad donde los estudiantes están realizando su formación académica de pregrado

Fuente: Elaboración propia

Con respecto a la distribución de los estudiantes en relación con el tipo de universidad se ha obtenido una población casi igualitaria, es decir, los estudiantes que se encuentran formándose en la universidad pública representan el 55.6\% (556 estudiantes) por mientras que los estudiantes que se encuentran formándose en la universidad privada representan el $44.4 \%$ (444 estudiantes). Un detalle que se ha tenido en el estudio es que se realizó a estudiantes que estudian en universidades en Lima capital y con una excepción de la Universidad Nacional del Callao que se encuentra en la provincia constitucional del Perú. 
Esta excepción se ha considerado debido que muchos ciudadanos que residen en Lima capital estudian en la universidad pública mencionada. Por lo cual, se consideró incluir a estos estudiantes que representan una población significativa. De manera de tener un mejor muestreo de la población de estudiantesse centró en el área de la ciencia que se encuentran estudiando, como se dijo se ha tomado la distribución de las carreras profesionales según la Universidad Nacional Mayor de San Marcos, específicamente como lo indica la Oficina Central de Admisión (OCA). Donde considera seis áreas de formación académica.
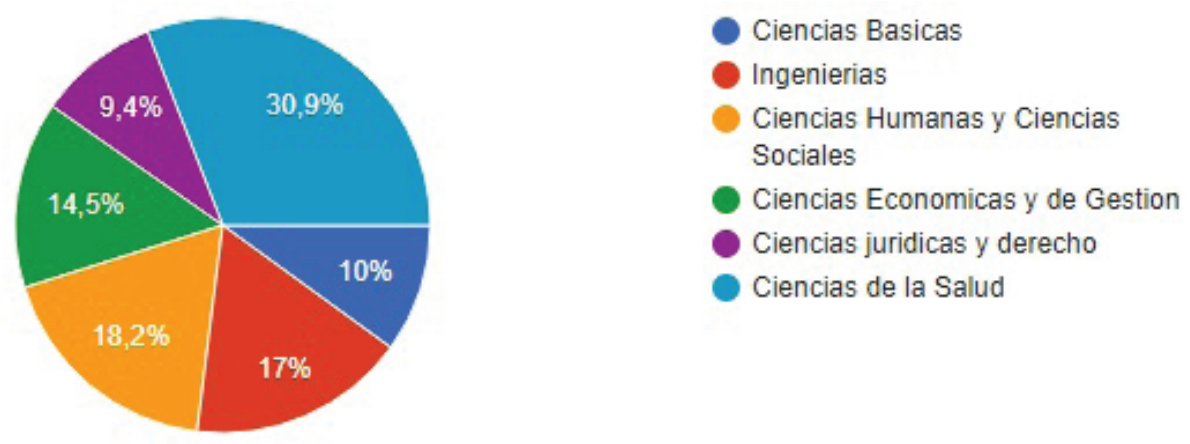

Gráfico 7. Distribución de las áreas de formación académica de los estudiantes Fuente: Elaboración propia

Dentro de la población considerada para el presente trabajo de investigación se ha obtenido una mayoría de estudiantes perteneciente a las ciencias básicascon $30.9 \%$ siendo un área más centrada a la investigación según los mismos comentarios de los estudiantes de acuerdo a su percepción académica. Después de esta área, se ha tenido en las demás áreas casi una población similar. Se ha obtenido un $18.2 \%$ del área de ciencias humanas y sociales, por mientras que se obtuvo un $17 \%$ del área de ingenierías, y un $14.5 \%$ del área de ciencias económicas y de gestión. Por otro lado, se ha recopilo un $10 \%$ del área de ciencias de la salud y un $9.4 \%$ del área de ciencias jurídicas y derecho.

Dentro de los estudiantes encuestados, se está relacionando con el año actual de estudios de pregrado, muchas de las carreras profesionales por no decir la mayoría cursan el año académico comprendido en dos se- 
mestres académicos, donde se ha distribuido todo en años académicos que están cursando en la universidad.

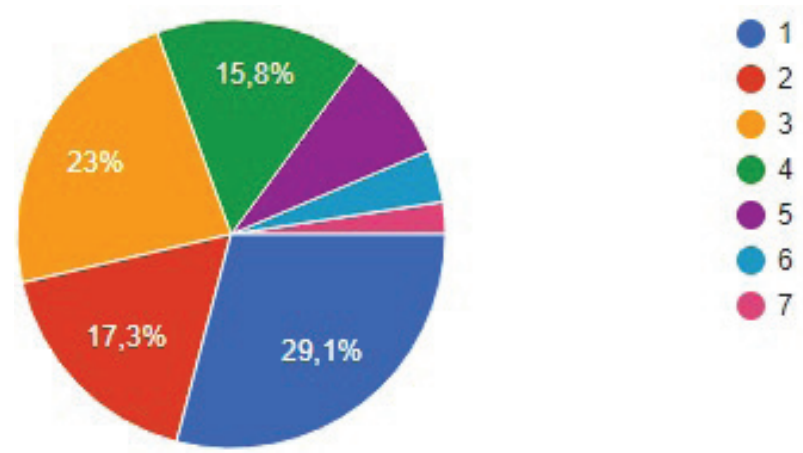

Gráfico 8. Distribución de los años académicos donde se encuentran realizando su formación académica los estudiantes universitarios

Fuente: Elaboración propia

En esta circunstancia con respecto al tiempo de formación académica universitaria, la gran mayoría de carreras profesionales en el país son de una duración de cinco años, a excepción de E.A.P. de Derecho (6 años) y la E.A.P. de Medicina Humana (7 años). De esta manera el estudiante ha declarado en el tiempo que viene formándose en la universidad.

Entre la población de estudiantes se ha tenido un 29.1\% que se encuentran en el primer año de su formación académica, seguido por una población de 23\% que se encuentran en el tercer año de formación. Luego se sitúa dos poblaciones importantes de la población estudiantil que el $17.3 \%$ del segundo año y un $15.8 \%$ pertenecientes al cuarto año. Las tres últimas poblaciones que corresponde a los últimos años de formación, teniendo en cuenta que la gran mayoría se encuentra en el último año de formación con un 8.5\%, y corresponde a su elaboración de sus trabajos de investigación mediante la modalidad de tesis (Bachillerato y Licenciatura) a excepción de las carreras de Derecho y Medicina Humana. De donde se tienen las poblaciones de sexto año con un total de 39 estudiantes (3.9\%) y la de séptimo año con un total de 24 estudiantes $(2.4 \%)$ donde solamente pertenecen a la carrera profesional de medicina humana de manera específica en su tiempo de internado para completar su formación académica. 
Como se ha observado durante las primeras gráficas, se tiene la visión de los datos generales de los estudiantes encuestados, con lo cual se podrá realizar la segunda parte de la encuesta y la más importante donde se enfocara la percepción académica de los docentes universitarios para mejorar la calidad de la educación superior del país.

La SUNEDU tiene 19 funciones explicitas que las expresa en su página web que se relaciona con la calidad de la educación superior. Yuna de sus funciones es la de proteger el derecho de los jóvenes a recibir una educación universitaria de calidad, y de esta manera, mejorar sus competencias profesionales. Y con respecto a los trabajos de investigación realizados por las universidades será asumido realizará la función de administrar el Registro Nacional de Grados y Títulos, bajo la consigna de brindar seguridad jurídica de la información que se encuentra registrada y garantizar su autenticidad. Este detalle será importante recalcar debido que la SUNEDU brindara sobre los logros académicos de los ciudadanos peruanos de todas las universidades tanto públicas como privadas. Esto conlleva un portal de transparencia para conocer sobre los grados académicos y los títulos profesionales que posee un ciudadano, de manera específica un docente universitario que es donde se centrara nuestra investigación, para ejercer la labor profesional que crea conveniente. De manera específica con respecto a la verificación de cualquier ciudadano de conocer sobre la formación académica universitaria es gratuita y de manera en tiempo real, debido que solamente se debe ingresar a la página web de la SUNEDU en su sección deServicios en línea, donde se encontrará el servicio si uno se encuentra en el Registro Nacional de Grados y Títulos, que se encuentra en el siguiente link: https://enlinea.sunedu.gob.pe/

De manera específica, el primer servicio en línea que brinda la SUNEDU que se encuentra en la esquina superior izquierda del Gráfico 9, que es para la verificación si uno se encuentra en el Registro Nacional de Grados académicos y Títulos. Luego, se presenta la ventana de la página web donde se realizará el ingreso de los datos necesarios para obtener la información deseada del profesional. Como se puede observar en el Gráfico 10 se solicita dos formas de ingreso de datos: por el ingreso del DNI o el ingreso del Nombre completo de la persona. 


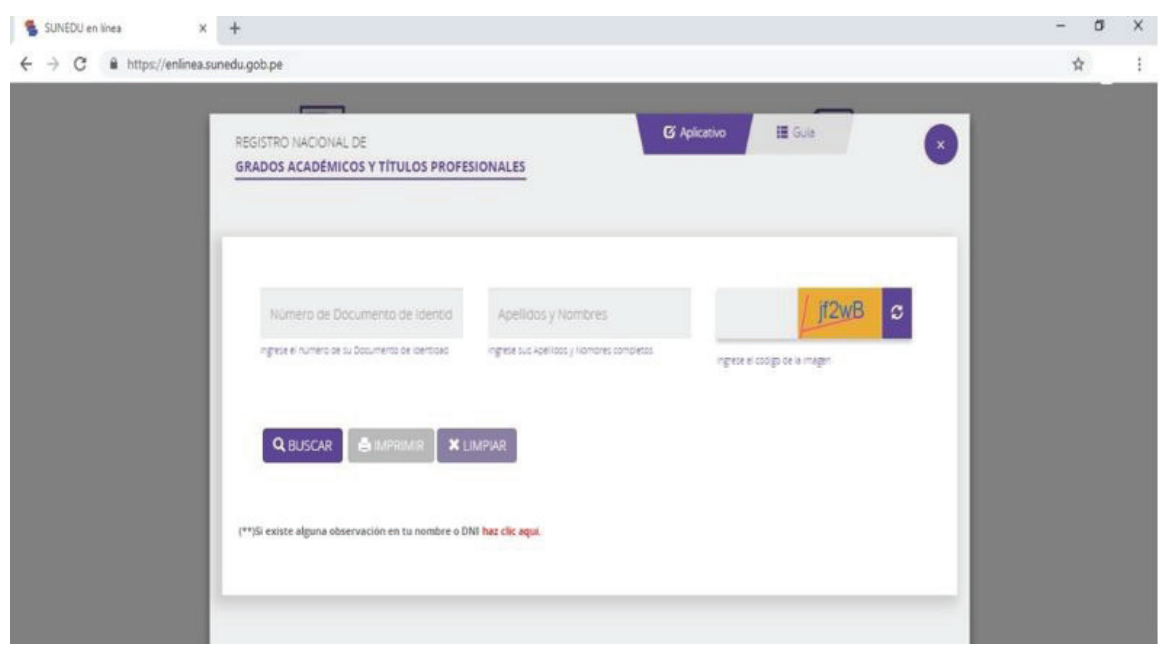

Gráfico 9. Registro Nacional de Grados Académicos y Títulos Profesionales Fuente: SUNEDU

Teniendo en cuenta el servicio en línea que se tiene en la página web podremos considerar estos servicios gratuitos que tiene todo ciudadano peruano o cualquier persona en general para conocer los grados académicos y/o título profesional que un ciudadano ante cualquier requerimiento que se tenga que realizar de manera inmediata. Ante este hecho, en nuestra población de estudiantes se consultó sobre este servicio que brinda la SUNEDU para que pueda reconocer los méritos académicos que pueda tener un docente universitario.

Se realizó algunas preguntas puntuales sobre la ley universitaria N³0220 que rige actualmente la educación superior y de la misma labor que realiza la SUNEDU. De esta manera, se puede conocer la percepción que se tiene de la misma ley y como la SUNEDU viene aplicando lo que la ley indica para mejorar la calidad de la educación superior en el país.

Realmente después que se haya dispuesto la ley universitaria, aún hay estudiantes universitarios que no la conocen totalmente o parcialmente. En este sentido, se ha reconocido que el $37 \%$ de la población considerada (370 estudiantes) pertenecen a la población de los estudiantes que pertenecen al primer y segundo año de formación académica en su mayoría. Por mientras, que el 63\% (630 estudiantes) de la población que con- 
oce parcial o completa la ley pertenecen a los últimos años de formación (tercer año a séptimo año) debido que han presenciado y experimentado la transición de la antigua ley a la nueva ley universitaria, desde esta perspectiva el conocimiento de la ley se basa en lo que brinda los cambios académicos que ofrece las nuevas directrices de la ley universitaria.
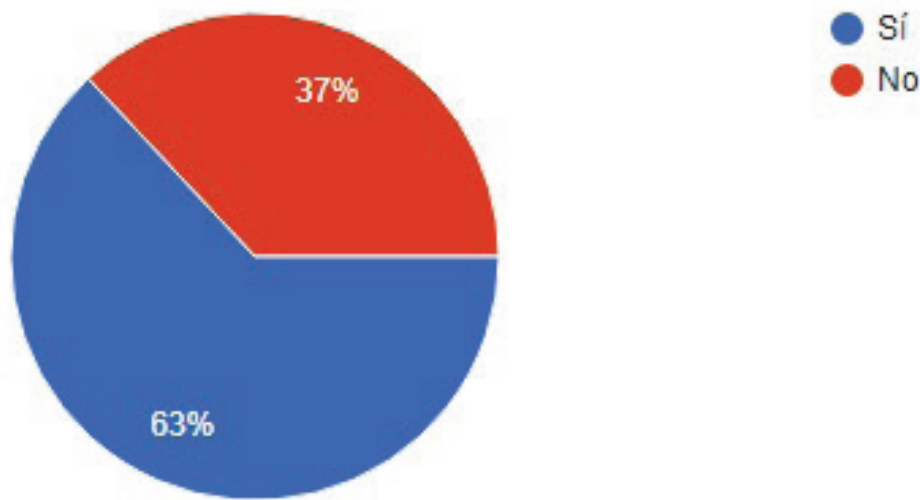

Gráfico 10. Distribución del conocimiento de la Ley Universitaria №30220

Fuente: Elaboración propia

La Superintendencia Nacional de Educación Superior Universitaria (SUNEDU) con respecto a la labor que realiza actualmente a favor de la calidad de la educación superior ha generado un cambio positivo para la calidad educativa de manera progresiva.
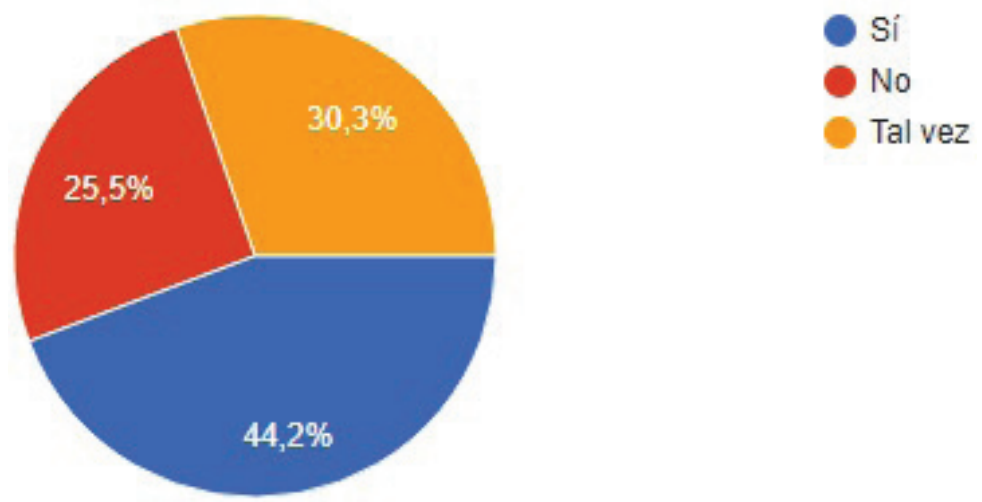

Gráfico 11. Distribución del conocimiento de la labor de la SUNEDU en cuanto a la formación universitaria de acuerdo a la ley universitaria $N^{\circ} 30220$

Fuente: Elaboración propia 
Desde una perspectiva social o la influencia que genera la labor de la SUNEDU ha sido algo muy poco percibida por los estudiantes encuestados, en cierto modo que los dictámenes que se pueden observar con más visibilidad es sobre el licenciamiento de las universidades, pero fuera de ese detalle pareciera que no realiza más funciones, lo cual no es cierto debido que viene trabajando en la aplicación de la actual ley universitaria. En este sentido, se ha tenido un $44.2 \%$ que si conoce la labor que realiza la SUNEDU, por mientras que un $25.5 \%$ no sabe que es lo que realiza fuera de la labor del licenciamiento de las universidades, y teniendo un $30.3 \%$ que está en duda sobre qué es lo que realiza la SUNEDU por la educación universitaria.

Teniendo estos lineamientos sobre el conocimiento de la labor de la SUNEDU que realiza para mejorar la calidad educativa, se enfocara ahora el trabajo de investigación sobre la percepción de la preparación académica de los docentes universitarios por parte de los estudiantes, y como la ley universitaria impulsa una formación académica de calidad para generar conocimiento científico.

Como se había mencionado, la ley universitaria en su capítulo IV de manera específica en su artículo 82, exige el grado de maestro o magister para la formación en el nivel de pregrado.

Con lo cual, se ha incrementado un nivel de preparación académica para poder impartir la docencia universitaria la cual en la antigua ley solo bastaba poseer el título profesional como mínimo.

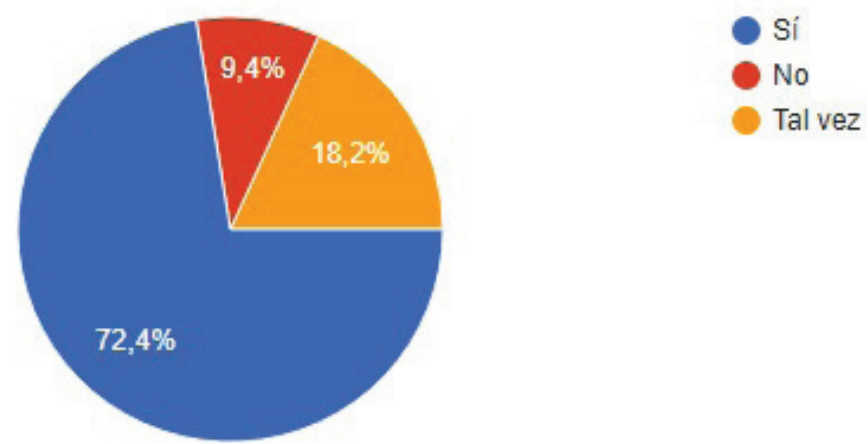

Gráfico 12. Distribución de la aceptación de los estudiantes ante la exigencia del grado de maestro (magister) para ejercer la docencia universitaria

Fuente: Elaboración propia 
Con esta perspectiva objetiva y directa, se puede observar la gran mayoría de estudiantes que aceptan este requisito para ejercer la docencia universitaria donde se ha obtenido un $72.4 \%$, por mientras que un 9.4\% ha indicado que no es necesario poseer el grado de maestro para ejercer la docencia, por mientras que un $18.2 \%$ expresan la duda sobre si este requisito es necesario u opcional para generar un cambio en la educación superior universitaria. En este momento, se viene a exponer un cuestionamiento que no debe ser catalogado como un menosprecio ante la formación académica que expresa en la ley universitaria en cuanto al requisito mínimo para ejercer la docencia universitaria que es el grado de maestro (magister).

De los docentes universitarios encuestados (400 catedráticos) se analizó que dentro de los docentes que son maestros (magísteres) en su mayoría (65\%) había realizado en maestría en educación, y de los docentes que están realizando sus estudios de maestría lo están haciendo en educación (70\%), de los que no están realizando los estudios de maestría, se consultó en que lo haría, y su respuesta fue en educación (39\%). Esto indicaría que los docentes universitarios que poseen su título profesional, realizan la maestría en educación para obtener el grado de maestro (magister) y así cumplir con el requisito que exige la ley universitaria.

Esta inferencia de los datos recolectados no quiere menospreciar a la maestría de educación, porque toda formación académica enriquece la preparación del profesional para poder realizar una mejor labor en su centro de trabajo. Pero por otro lado, una de los pilares de la ley universitaria es de subir el nivel académico y la calidad de la educación, y quizás esto se pueda realizar con docentes que realizan una maestría en su especialidad para que puedan generar conocimiento, proyectos, investigaciones que mejoren la formación académica de los estudiantes. Este comentario es el centro de la secuencia de preguntas sobre esta perspectiva que los estudiantes perciben en los docentes universitarios cuando realizan sus clases en los cursos de la malla curricular de la carrera profesional.Por lo cual, se realizó la pregunta relacionada en la sección sobre la percepción de los estudiantes en cuanto a la formación de sus docentes. Y como los mismos estudiantes se ven a sí mismos relacionando la formación y la preparación de los docentes. Este enfoque busca que el docente universitario genere conocimiento y no solamente transmitir conocimiento. 
Y también como lo manifestó la comisión nacional para la segunda reforma universitaria (2002) en el informe final que se realizó sobre la universidad peruana enfocándose en las razones para una nueva reforma universitaria, siendo un preámbulo para la creación de la actual ley universitaria. Generando una situación que se necesitaba elevar la formación científica, humanística y social con nuevos rumbos en la preparación de los estudiantes como el futuro del país.

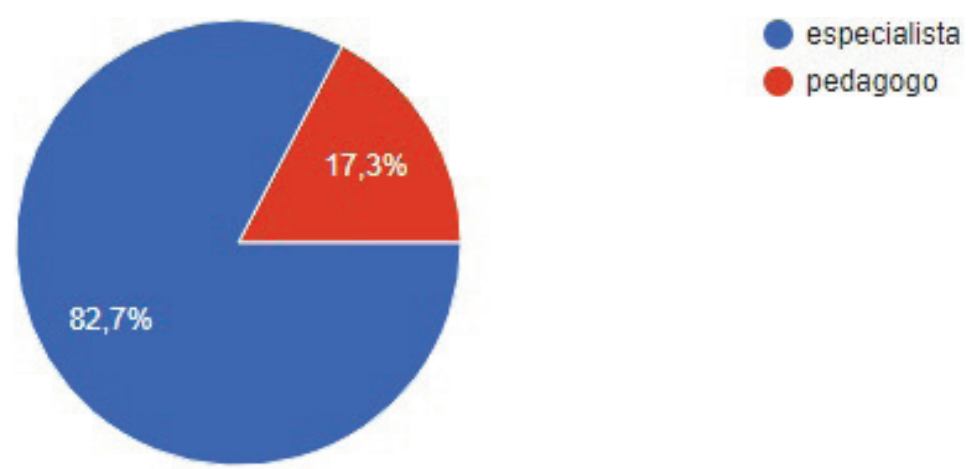

Gráfico 13. Distribución de los estudiantes ante la preferencia del docente universitario en cuanto su formación académica

Fuente: Elaboración propia

Realmente con respecto a la preferencia de los estudiantes en cuanto a la formación académica de los docentes, se ha obtenido un $82.7 \%$ prefieren a un docente universitario especialista antes que un pedagogo, por mientas que un $17.3 \%$ prefieren a un pedagogo de manera preferencial. Es claro pensar, que un estudiante prefiere a un docente que reúna las dos características mencionadas, especialista debido al conocimiento actual y técnica que tiene del curso y pedagogo para transmitir de la mejor manera los conocimientos técnicos que se tiene. Pero en esta circunstancia se enfoca en la elección de una característica para poder ver la elección de una preferencia únicamente para el desarrollo de los temas del curso universitario.

Desde esta perspectiva de que el docente universitario tenga conocimientos y experiencia sobre el curso, y se realizó la pregunta a los estudiantes, sobre la preferencia de los estudios de maestría para generar un mejor impacto en la formación académica. 


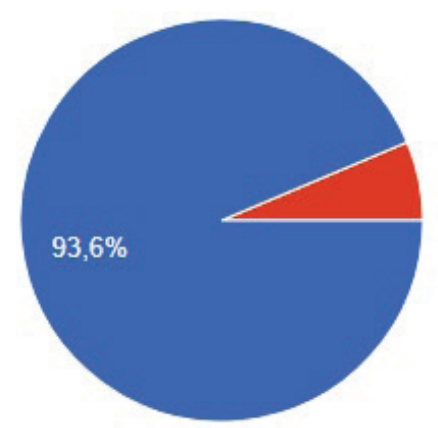

especialidad

en otra area

Gráfico 14. Distribución de los estudiantes ante el área de la primera maestría de los docentes universitarios para los cursos de pregrado

Fuente: Elaboración propia

Una de las habilidades de los profesionales, es de seguir aprendiendo cada día más, después de obtener el título profesional, en adelante uno tiene una gran cantidad de oportunidades académicas profesionales como cursos de especialización, diplomados, workshops, seminarios donde te permiten aprender e investigar más sobre los temas de interés para abordar los retos actuales que la sociedad exija en la preparación de los profesionales como lo manifiesta el IPEBA (2011).

Esta formación académica que permite un crecimiento profesional es formación diferenciada a la preparación que brinda una maestría, debido que eleva un grado académico más a la presentación profesional. De esta manera, de acuerdo a los objetivos de la ley universitaria que busca enfocarse en la investigación científica se debe recurrir a profesionales especialistas en su carrera profesional, sin menospreciar su formación en otras áreas de las ciencias afines, por lo cual la pregunta realizada sobre la primera maestría de formación va enfocada de tener el grado académico de maestro en la línea directa de su formación de pregrado.

En este punto, el 93.6\% (936 estudiantes) de los estudiantes respondieron que preferían un docente con grado de magister en su especialidad de pregrado. Por mientras que un 6.4\% (64 estudiantes) prefirieron a docentes que maestría en algún área afín a su formación de pregrado. Realmente, se puede opinar de diferentes ángulos esta perspectiva de poseer docentes con el grado de maestro en la especialidad como que no es indispensable, esta visión es distinta a la enunciada en la ley universitaria 
con respecto al requisito del grado de maestro para ejercer la docencia universitaria.

En esta perspectiva de la calidad de la educación superior, los estudiantes siempre deben estar pendientes en cuanto a las referencias del docente, por lo cual se realizó la pregunta al interés de conocer la carrera profesional del docente universitario de manera rápida y de información confiable.

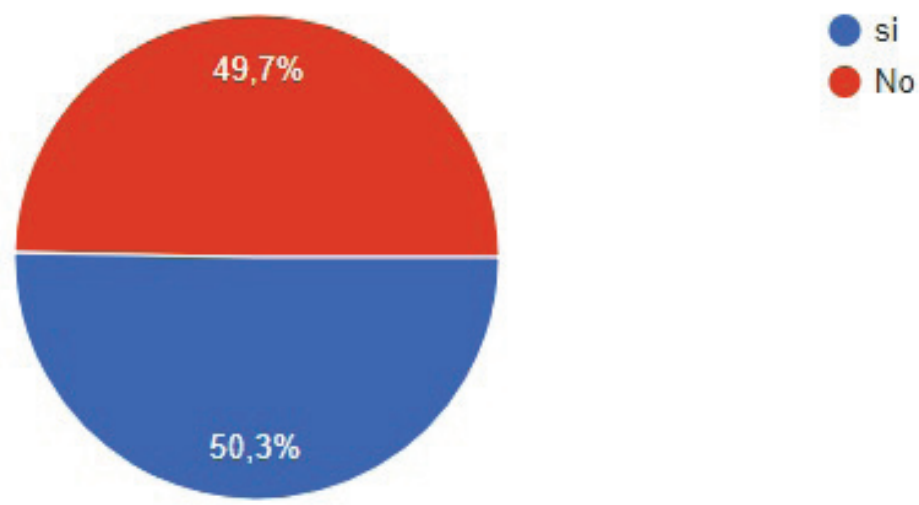

Gráfico 15. Distribución de la investigación que realizan los estudiantes hacia sus docentes con respecto a su formación académica

Fuente: Elaboración propia

En estas circunstancias donde la información se puede encontrar en el internet, y de manera abundante, la investigación debería ser más sencilla pero a la vez más difícil, no por la escasez de información sino por la calidad y veracidad de la información. En este sentido se obtuvo casi la mitad de la población que afirma investigar a los docentes, con una población del 50.3\%. Y el complemento que afirmo que no investiga a sus docentes con un $49.7 \%$, generando las perspectivas sobre el interés académico hacia los docentes.

Este Gráfico nos ayudará a observar si los estudiantes se dedican a investigar sobre la formación académica de sus docentes esperando obtener una formación más especializada que brinde una mejor preparación.Con la distribución presentada en el Gráfico 15 se puede obtener una siguiente interrogante sobre la percepción de los docentes y la maestría 
que han realizado. Por lo cual, de los estudiantes que afirmaron que sí investigan a sus docentes sobre su formación académica (503 estudiantes).

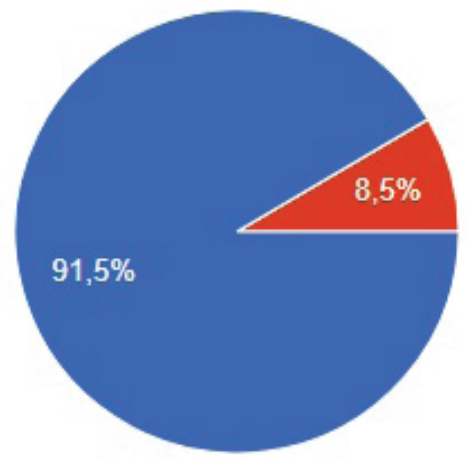

- especialista en su area

especialista en area afin

Gráfico 16. Distribución de la motivación de los estudiantes que investigan al docente universitario ante su formación académica

Fuente: Elaboración propia

De los estudiantes que realizan alguna investigación sobre la información académica y la preparación profesional de sus docentes universitarios. Se ha obtenido una gran población que prefieren a un docente especialista en su área, esta población es de 91.5\%. Por mientras que un 8.5\% prefieren un especialista en un área afín a su carrera profesional. En este aspecto, se puede tener opiniones diferentes y perspectivas distintas en la formación que deseen obtener en el transcurso del curso. Hasta este momento, las preguntas han estado enfocadas a la investigación que el estudiante pueda enfocarse a una formación más técnica posible, y en este sentido, se espera que un docente formado en pregrado y apoyado con una maestría en su especialidad mejorar la educación superior de pregrado. Como se realizó una pregunta dedicada a los estudiantes que suelen investigar la formación de sus docentes, también se realizó una pregunta a los que no suelen realizado tomando en cuenta que a veces no se conoce algún medio rápido y veraz con respecto a la información de los docentes universitarios.

En este sentido, habíamos mencionado en la sección anterior con respecto a uno de los servicios de la Superintendencia Nacional de Educación Superior Universitaria (SUNEDU) que permite poder visualizar la 
información de la formación académica de la educación superior. Y ya se había indicado que este servicio es gratuito y sencillo para poder visualizar la información validada por la Superintendencia que garantiza la autenticidad de los diplomas emitidos por las universidades, brindando un acceso libre y seguro de un derecho de todo estudiante de conocer sobre la formación de sus docentes, y más aún, el libre conocimiento de los grados académicos y títulos profesionales de cualquier profesional en el rubro del desempeño laboral.

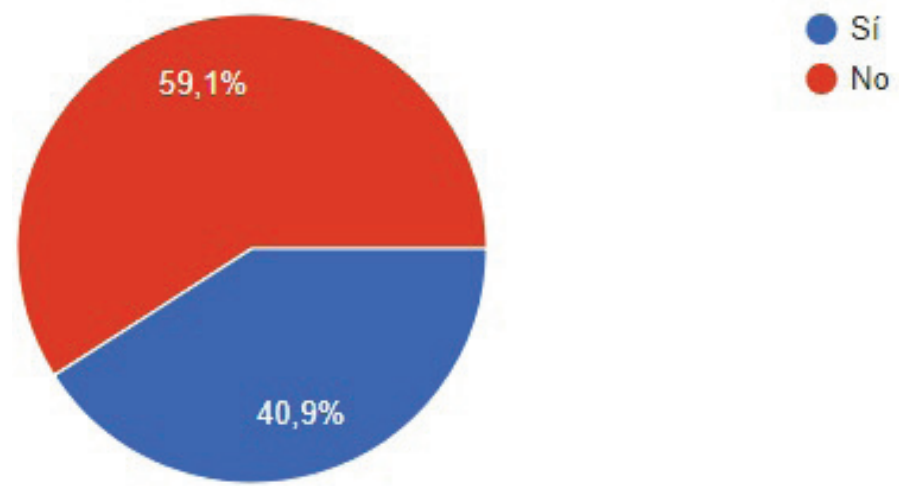

Gráfico 17. Distribución del conocimiento del servicio de la SUNEDU para visualizar los grados académicos y títulos profesionales de los docentes

Fuente: Elaboración propia

Esta situación que surge ante el desconocimiento de este servicio tan fundamental e importante que un ciudadano pueda acceder de manera rápida y verídica para saber si una persona es quien dice ser en el aspecto de la formación académica. En nuestro trabajo de investigación se centra en el conocimiento de los docentes universitarios, y una herramienta referencial sobre la formación académica de los docentes para los estudiantes y así buscar una mejor formación universitaria.

Con una población de 59.1\% que si conocía del servicio en la página web de la SUNEDU en su mayoría (75\%) de esta población han sido estudiantes que investigaba la formación de sus docentes. Por mientras que un $40.9 \%$ no conocía de este servicio lo cual se relacionó con la población que no investigaba a sus docentes (85\%). No cabe la duda que el índice de conocimiento de la formación académica de los docentes está enorme- 
mente relacionada con el conocimiento del servicio de la SUNEDU en su página web donde ya se había dicho que es una consulta rápida donde se puede obtener la información deseada bien con el número del Documento Nacional de Identidad (DNI) o ingresando el nombre completo del docente, significando que la obtención de la información es validada por la misma SUNEDU.

El conocimiento de los docentes es de vital importancia para una formación académica de calidad debido que es uno de los objetivos de la actual ley universitaria y una de las funciones de la SUNEDU. En esta línea, se presenta una interrogante a los estudiantes sobre la percepción de la calidad de la educación que están recibiendo por parte de la universidad. Esta es una de las funciones que la universidad debe cumplir con respecto a sus estudiantes que deben formarse adecuadamente para poder brindar un servicio profesional, técnico, humanístico para el crecimiento de la sociedad y del país.
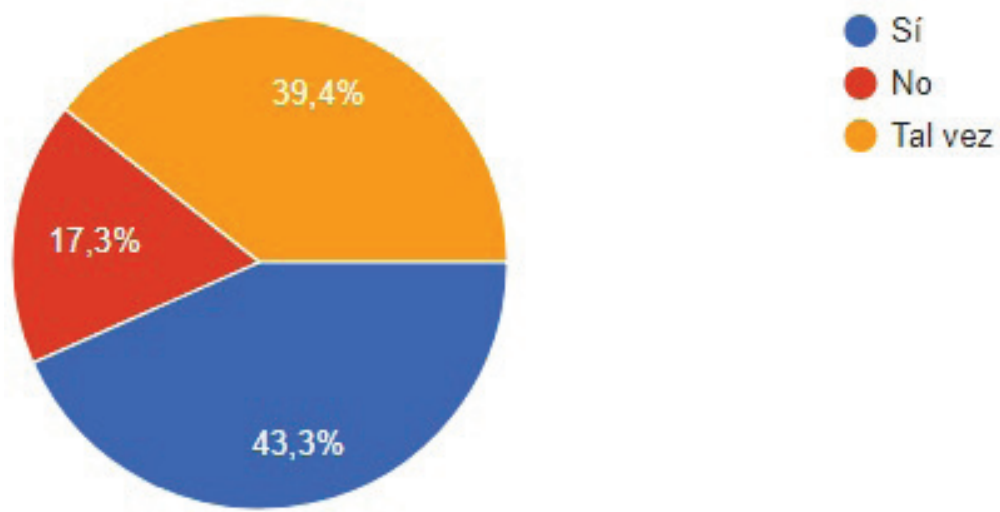

Gráfico 18. Distribución de la percepción sobre la formación universitaria con respecto a la preparación para el actual mercado laboral

Fuente: Elaboración propia

La distribución de la aceptación o rechazo de la formación académica que un estudiante puede percibir como un ciudadano que se prepara para afrontar los problemas que acucian a la sociedad. En este sentido, una población de $43.3 \%$ afirman que reciben una formación adecuada que les permitirá afrontar el actual mercado laboral donde cada día es más competitivo, pero se tiene una población de $17.3 \%$ que 
no está conforme con la formación académica mientras que un 39.4\% se mantienen en un duda si la formación recibida es la más idónea para el mercado laboral en que se sitúa actualmente. Pero con respecto a estos datos, los que están a favor de la formación se sitúan en el segundo y tercer año, por mientras que los que están en duda se sitúan entre el tercer y cuarto año.

Sin embargo la población que rechaza se sitúa en el último año de formación lo cual llevaría a reflexionar este detalle debido que son los estudiantes próximos a egresar de la universidad. Una situación complicada de expresar sobre la calidad de la formación académica en la universidad es el docente que sea calificado para impartir las clases de los cursos de pregrado donde todo curso está diseñado como una parte esencial de la malla curricular. Por lo cual debe impartirse de la mejor manera con los temas designados por el silabo del curso buscando la comprensión y la aprehensión de los temas enfocados a la investigación y la generación de nuevos conocimientos.

Por lo cual, se consultó de manera inicial a varios estudiantes sobre si sus docentes son los más idóneos para el dictado de ciertos cursos, y de los que investigaban a sus docentes comentaron que encontraron docentes ligeramente distante a la formación que requiere el perfil del docente para el curso, y este hecho, se centraba más en las universidades privadas que las públicas. Bajo esta perspectiva se centró una pregunta que buscaba una percepción más adecuada sobre el perfil docente para el curso universitario. Con lo cual se formuló de la siguiente manera la pregunta con respecto a este tema.

¿Crees que los cursos deban ser impartidas por los especialistas del área (cursos de matemática por matemáticos, cursos de ingeniería por ingenieros, cursos de química por químicos, cursos de biología por biólogos, cursos de economía por economistas, cursos de derecho por abogados, cursos de pedagogía por educadores, cursos contabilidad por contadores, cursos de física por físicos, cursos de gestión por administradores, etc.) o por un especialista afín a estos cursos? 


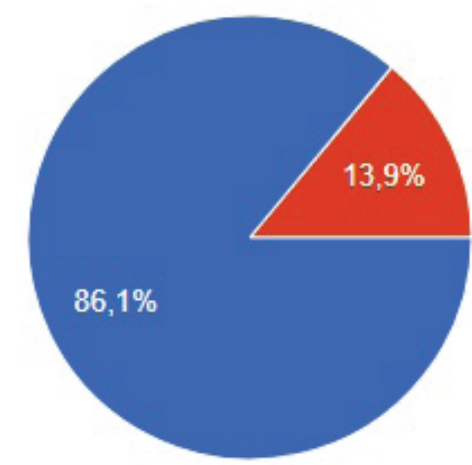

especialistas del area

especialista afin al area

Gráfico 19. Distribución de la elección con respecto a los docentes que deben impartir los cursos universitarios de acuerdo a su especialidad

Fuente: Elaboración propia

Uno de las grandes disyuntivas es cuando al a preparación de los docentes para impartir las clases o la cátedra de un curso, por cuanto, en el sentido del orden adecuado los especialistas deberían impartir el curso el cual son conocedores de los temas y que pueden generar puentes de investigación para generar un mayor conocimiento. No se puede negar que muchos especialistas de un área afín puedan impartir los temas con un alto nivel académico. Quizás el mismo orden que se pueda orientar la labor del docente universitario como la preparación especializada en cada área de la ciencia deba ser el mejor pilar para mejorar la calidad de la educación superior universitaria así como lo hacen otros países latinoamericanos.

La población de estudiantes que prefieren a un docente especialista en el área ha sido de un $86.1 \%$ por mientras que se ha obtenido un $13.9 \%$ prefieren un docente especialista en un área afín. En esta pregunta se consultó algunos de sus docentes a los que investigaron y se encontraron circunstancias donde había una mayor incidencia en la universidad privada que la pública como se había comentado anteriormente.

Los estudiantes que habían investigado a sus docentes eran licenciados en educación y estaban dictando cursos de matemática, química, física a nivel superior, lo cual ha sido un detalle bastante particular donde una normativa debería darse, no tanto porque no posean los conocimientos del curso sino más bien en orden de la catedra universitaria donde se tiene una mayor exigencia en la investigación y generación de cono- 
cimiento más aun ahora con la actual ley universitaria. Por mientras que los profesores que son licenciados en educación tienen su propia ley, la ley $\mathrm{N}^{\circ} 24029$, y su reglamento de la ley del profesorado que sigue vigente de acuerdo al Ministerio de Educación (MINEDU) que exige ser licenciado en educación para ejercer la docencia en los colegios nacionales tanto de nivel primario como de nivel secundario. Y en el mismo reglamento indica lo siguiente:

El personal que labora en el nivel superior del sistema educativo se rige por un reglamento especial que determina su jornada de labor, titulación profesional, remuneraciones y demás obligaciones y derechos.

Esta referencia del reglamento de la ley del profesorado hace una vinculación a la ley universitaria. Esto no quiere decir, que un licenciado en educación pueda obtener un título profesional de otra profesión y pueda acceder a la cátedra universitaria, como también lo han realizado muchos profesionales que han obtenido su título profesional en educación. Este hecho, se ha contrastado con respecto a la población de docentes encuestados (400 docentes) donde muchos de ellos tiene su licenciatura en educación y otra licenciatura en otra carrera profesional (24\%), y del mismo modo, profesionales han obtenido su título profesional en educación por complementación pedagógica (8\%) de los docentes considerados en la encuesta para el presente trabajo de investigación.

Y desde aquí, se evaluó una pregunta para ser respondida en relación a la anterior, que se refiere a la exigencia y al conocimiento que permita generar nuevas sendas en la investigación, con lo cual la formación universitaria permitiría una mejor formación científica enfocada a una educación de calidad. En los últimos años se ha ido reformando muchos aspectos del enfoque de la educación y de la investigación como lo va direccionando el Consejo Nacional de Ciencia, Tecnología e Innovación Tecnológica (CONCYTEC) para los docentes investigadores que los mantiene registrado en el Registro Nacional de Investigadores en Ciencia y Tecnología (REGINA) que utiliza el Directorio Nacional de Investigadores (DINA) como fuente de información para la calificación correspondiente.

Teniendo esta referencia sobre la investigación que se realiza en el país, los estudiantes se pueden formar adecuadamente en el área de la investigación mediante los cursos, proyectos, guías científicas. Por lo cual, 
el docente especialista en su área es de vital importancia para generar cambios positivos no solamente científicos sino también humanista y social. Con lo cual, se formuló la siguiente pregunta sobre la percepción de la formación académica que se recibiera ante un docente especialista bien del área o de un área afín.

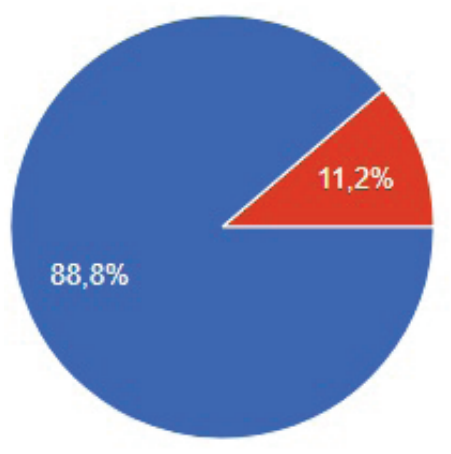

docente especialista en el area

docente especialista en un area afin

Gráfico 20. Distribución de la percepción ante la formación académica que se puede obtener ante el docente especialista en su área o en un área afín

Fuente: Elaboración propia

Dentro de una perspectiva más enfocada a la investigación y a la generación de conocimiento en la búsqueda de una mejor sociedad, como lo había comentado Pino y Flores (2017), se tiene un lineamiento centrado a tener buenos docentes y que estén centrados en la línea de carrera escogida, lo que desmerece obtener más conocimientos en áreas afines, si se puede complementar con la especialidad es lo más adecuado debido que ahora las investigaciones científicas son interdisciplinarias.

Con respecto a la pregunta se obtuvo un población de $88.8 \%$ consideraron que cursar con docente de la especialidad del área es mucho más beneficioso para su formación académica y profesional, por mientras que un $11.2 \%$ consideraron cursarlo con un docente de una especialidad afín. Ambas decisiones son correctas considerando lo que se espera del curso y de la formación que uno quiera recibir y como se alinea 
al enfoque de formación académica y laboral que se quiera ejercer en el futuro.

Ahora se presentará algunos comentarios sobre esta situación que se ha presentado en la educación superior peruana. Después de las preguntas de alternativa múltiple se realizó algunas preguntas de respuesta libre para conocer su percepción ante esta realidad. Se ha escogido tres preguntas que se expondrá en el presente trabajo.

¿Qué opinas de los docentes que tienen maestrías que no son de su especialidad, sino en otra área?

- Desean complementar su formación para ser especialista en ambos, pero uno con maestría en su especialidad le saca ventaja.

- Deberían tener una maestría en su especialidad primero pero a su vez no está de más tener especialidad en otras áreas.

- Que deberían dedicarse a dictar clases en lo que compete a su área, ya que al final, los perjudicados son los alumnos.

- Los docentes con maestrías en otras áreas, no están tan actualizados en el tema, por el hecho de que no es su área, uno como estudiante se da cuenta que el curso no es completo, solo te enseñan la forma de estudiarlo y pasar el curso.

- Creo que cada docente debería dictar su especialidad, así, lógicamente sabría absolutamente todo sobre su área y poder responder sin dificultad cualquier pregunta de un alumno.

\section{¿Qué opinas sobre la ley universitaria que solamente exija el grado de magister y NO el grado de magister en la especialidad para ser docente universitario?}

- Me parece que no se están dando cuenta que al final los perjudicados somos nosotros como estudiantes, ya que la competencia laboral ahora es mayor, por otro lado el nivel de educación con un docente que no está especializado en su área no nos ayuda a crecer en educación y al menos llegar al rango de enseñanza con otros países. 
- Creo que deberían pedir ambos para que la educación mejore, o de otro modo, pedir primero la especialización y que cuando enseñen a la par lleven la maestría.

- Deberían de exigir que sea de especialidad ya que así daría una buena enseñanza

- Creo q debe replantearse esa ley para q los profesores tengan su especialización y enseñe de mejor manera

- Pues que genera una probabilidad muy alta de que el docente no pueda desarrollar el curso de manera comprensiva para los alumnos.

- Que no busca la especialización de la carrera que poseen y no buscan tener conocimientos actuales de los cursos que imparten. quizás busquen algo fácil para seguir dictando en la universidad.

Realmente en este punto, se ha considerado las opiniones favorables y desfavorables para los estudiantes en cuanto a estas preguntas de respuesta libre debido que la percepción que cada estudiante tiene de la formación del docente, la didáctica del docente, la metodología del docente, el enfoque que realiza el docente es comprendida, aprehendida de distintas formas lo que genera estos diversos comentarios.

\section{Conclusiones}

Después de toda la investigación con respecto a la percepción de la formación docente que se requiere para ejercer la docencia universitaria de acuerdo a la actual ley universitaria, se ha encontrado diversas opiniones sobre estos lineamientos tanto en general que expone la ley como en específico para ejercer la docencia.

De todo lo comentado sobre la ley universitaria, la SUNEDU, los docentes universitarios y los estudiantes, se puede enunciar las siguientes conclusiones de nuestro trabajo de investigación.

- Dentro de los docentes encuestados (400 docentes) se obtuvo una cantidad significativa ha realizado una maestría en un área 
afín a su formación de pregrado, entre ellas de mayor incidencia la maestría en educación.

- Dentro de los estudiantes encuestados (1000 estudiantes) se ha obtuvo una cantidad significativa que no conoce la ley universitaria y las funciones que realiza la SUNEDU, sobre todo el servicio en línea para saber la formación académica de los docentes universitarios sobre sus grados académicos (bachillerato, maestría, doctorado) y su título profesional correspondiente.

- La excelencia académica enfocada a realizar investigación científica se ve más notoria en complemento a la formación académica brindada en los estudiantes en los docentes especialistas en sus áreas respectivas más que los docentes especialistas en áreas afines.

- Se cree que mejorará la educación superior si se modificara el artículo de la ley universitaria referente al requisito para ejercer la docencia universitaria a nivel de pregrado donde exige el grado de maestro por el grado de maestro en la especialidad.

\section{Referencias Bibliográficas}

Barahona Migueles, Jeileen \& Medina, Edwin. (2015). Percepción de los docentes y estudiantes hacia el proceso enseñanza-aprendizaje de la investigación en la Facultad de Ingeniería, ciudad universitaria, 2014. Revista Portal de Ciencias, $\mathrm{N}^{\circ} 8$, junio 2015. DOI: http://dx.doi.org/10.5377/pc.v8i0.2160

Comisión Nacional para la Segunda Reforma Universitaria (2002). Diagnóstico de la Universidad Peruana: Razones para una nueva reforma universitaria. Presidencia de la República y Congreso de la República del Perú. Recuperado en: http://www4.congreso.gob.pe/congresista/2001/liberico/universidadfinal.pdf

Consejo Nacional de Ciencia, Tecnología e Innovación Tecnológica - CONCYTEC (2015). Reglamento de calificación, clasificación y registro de los investigadores del Sistema Nacional de Ciencia, Tecnología e Innovación Tecnológica - SINACYT. CONCYTEC. Recuperado en: https://portal.concytec.gob.pe/images/noticias/Propuesta_del_nuevo_Reglamento_del_investigador.pdf

Coraggio, José Luis. (1996). Renovación universitaria y pedagógica de la enseñanza superior. Exposición en el Seminario sobre "Las Nuevas Universi- 
dades a finales del siglo XX". Universidad Nacional de General Sarmiento, San Miguel. Argentina. SCielo.

Guerra-García, Roger. (1979). La investigación científica en el Perú en los años veinte. Revista de la Universidad Católica.

Instituto Peruano de Evaluación, Acreditación y Certificación de la Calidad de la Educación Básica (2011). Dos décadas de formación profesional y certificación de competencias: Perú 1990 - 2010. Programa Educación Básica para Todos. IPEBA. Recuperado en: https://www.sineace.gob.pe/wp-content/ uploads/2015/06/Dos-D\%C3\%A9cadas-de-Formaci\%C3\%B3n-Profesional-y-Certificaci\%C3\%B3n-de-Competencias.pdf

Ministerio de Educación del Perú. (2003). Ley General de la Educación, ley ${ }^{\circ}$ 28044. Ministerio de Educación. Recuperado de http://www.minedu.gob. pe/p/ley_general_de_educacion_28044.pdf

Ministerio de Educación del Perú. (2012). Reglamento de la Ley General de la Educación, ley $\mathrm{N}^{\circ}$ 28044. Ministerio de Educación. Recuperado de http:// www.minedu.gob.pe/normatividad/reglamentos/RegProfesorado.php

Ministerio de Educación del Perú. (1990). Reglamento de la Ley del Profesorado, $\mathrm{N}^{\circ} 24029$ y su modificación de la ley $\mathrm{N}^{\circ}$ 25212. Ministerio de Educación. Recuperado de http://www.minedu.gob.pe/comunicado/pdf/normativa-2018/ley-28044/ds-011-2012-24-11-2017.pdf

Ministerio de Educación del Perú. (1984). Ley del Profesorado, ley № 24029. Ministerio de Educación. Recuperado de http://www.minedu.gob.pe/normatividad/leyes/Ley24029.php

Ministerio de Educación del Perú. (1995). Ley Universitaria, ley № 23733. Ministerio de Educación. Recuperado de http://www.une.edu.pe/transparencia/ informacion/LeyUniversitaria_actualizada020508.pdf

Ministerio de Educación del Perú. (2014). Ley Universitaria, ley $N^{\circ} 30220$. Ministerio de Educación. Recuperado de http://www.minedu.gob.pe/reformauniversitaria/pdf/ley_universitaria.pdf

Ministerio de Educación del Perú. (2016). Currículo Nacional de la Educación Básica. Recuperado de: http://www.minedu.gob.pe/curriculo/pdf/curriculo-nacional-2016-2.pdf

Oficina Central de Admisión (2016). Catálogo de carreras profesionales UNMSM. Universidad Nacional Mayor de San Marcos. Recuperado de http://www. grupopitagoras.com/assets/catalogoadmision20171.pdf 
Pino Romero, Neisser \& Flores Barrenechea, Brisaida Isabel (2017). Percepción de una Formación Académica enfocada a la Investigación Científica constante en la Universidad Nacional Mayor de San Marcos. Pensamiento Crítico, v. 22 , n. 2, p. 127-158, feb. 2018. ISSN 2617-2143. Recuperado en: http://revistasinvestigacion.unmsm.edu.pe/index.php/econo/article/view/14334

Superintendencia Nacional de Educación Superior Universitaria (2015). Historia y Funciones. Ministerio de Educación del Perú. Recuperado en: https:// www.sunedu.gob.pe/historia/

Posgrado - Universidad Nacional Mayor de San Marcos (2018). Requisitos para postular a un Posgrado. Universidad Nacional Mayor de San Marcos. Recuperado de: http://posgrado.unmsm.edu.pe/requisitos/

UNESCO (2015). Replantear la educación ¿Hacia un bien común mundial? Recuperado de: http://unesdoc.unesco.org/images/0023/002326/232697s.pdf

Vargas D'uniam, Jessica; Chiroque Landayeta, Enrique; Vega Velarde, María Vanessa (2016). Innovación en la docencia universitaria. Una propuesta de trabajo interdisciplinario y colaborativo en educación superior. Educación Vol. XXV, N 48, pp. 67-84.http://dx.doi.org/10.18800/educacion.201601.004 